\title{
Relações devastadas
}

\section{Liliane Ribeiro Barbosa}

Doutoranda do programa de Pós-graduação em Psicanálise, Saúde e Sociedade da Universidade Veiga de Almeida - UVA. 


\section{Resumo}

O presente artigo realiza uma proposta de estudo voltada para a relação mãe-filha. Utilizam-se fragmentos de dois casos que correspondem ao percurso analítico de duas mulheres, cujos impasses em suas vidas amorosas parecem evidenciar aquilo que Lacan (1972), na esteira de Freud, nomeou de devastação. Para efetivar sua proposta, o artigo inicia-se com a revisão do conceito freudiano de 'feminilidade' e correlatos. Prossegue com o estudo das fórmulas quânticas da sexuação e do gozo feminino, recorrendo a textos de Lacan e de alguns comentadores de orientação lacaniana. Salienta a função da mãe como primeiro objeto de amor das crianças de ambos os sexos e sua repercussão na vida adulta de cada sujeito.

Palavras-chave: Devastação. Feminino. Fórmulas quânticas da sexuação. Gozo feminino.

\section{Abstract}

The current article conducts a proposal for study devoted to the relationship between mother-daughter. Two fragments of cases are used that correspond an analytical reflection of two women, whose impasses in their loving lives seem shows what the Lacan (1972) appointed devastation on Freud's teaching. To make its proposal, the dissertation begins with a revision of the Freudian concepts about femininity and related themes. This is followed by the study of the four formulas of sexuation and the feminine enjoyment, consulting others authors of lacanian orientation. Emphasises that mother function it's the first object of love on children and questioned the repercussion of this on theirs adults lives.

Keywords: Devastation. Feminine. Quantic formulas of sexuation. Enjoyement feminine. 


\section{Introdução}

O presente estudo dialoga com aquilo que FREUD (1932-1933 [2006]) em seu brilhante texto Feminilidade já havia indicado: a dura realidade da relação entre a mãe e a filha decorre de uma antiga relação pré-edipiana de longa duração e plena de afetos negativos (ódio, inveja). Esta última pode ter consequências na futura relação de uma mulher com um homem. Visa também fornecer uma base teórico-conceitual e sua aplicação prática sobre uma temática ainda tão enigmática e complexa como o fenômeno da devastação. Este último termo, denominado por LACAN (1972 [2003]) em sua elaboração das fórmulas quânticas da sexuação, que revela um acréscimo relevante à teoria freudiana.

No que tange às falhas da mãe, essas comparecem sempre no inconsciente, mesmo que o sujeito não as censure. Comparece a relação considerada inesquecível: a da devastação que se dá entre mãe e filha. Freud (1927-1931/1996) percebera que na ligação da mãe com a menina, o caminho que esta última percorre, ou melhor, se fixa, é muito mais terrível que o do menino. A devastação é entendida por ser uma mistura entre o corpo da mãe com o da filha. Há um embate entre as duas, à espera de uma identificação quanto à feminilidade, mas que não se encontra. Em resposta a essa falta de referencial, aparecem o ódio, a loucura e o exagero. Assim, para dar prosseguimento aos argumentos que subsidiarão os casos escutados em minha clínica e, por sua vez, justificam este artigo, apresentarei uma breve exposição dos mesmos.

Érica é uma paciente que tentou se matar, atirando-se na rua após ter visto o filme "O cisne negro" (ARONOFSKY, D. et al, 2010) e ter-se identificado com a personagem Nina. Revela a angústia de uma filha que tenta ocupar o lugar das demandas maternas - lugar este de puro capricho. Já Maria Antonieta, a paciente cuja incompreensão quanto ao motivo dos homens não a namorarem e não acreditarem nela é demonstrado pelo papel preponderante de sua mãe e de sua irmã em sua vida. A frase "Somos um bloco... Somos grudentas", reflete o que ela alimenta nos homens: o seu real afastamento de qualquer tentativa de se relacionar com eles, uma vez que não se permite criar lugar para eles. No mesmo sentido, ela também tenta ocupar o lugar do namorado de sua mãe, tratando-o de maneira completamente insana e infantil. 


\section{A sexuação da mulher}

Para dar continuidade a este tema, percorrerei o sinuoso caminho da sexualidade feminina, partindo das concepções e formulações acerca dos complexos de Édipo e de castração que Freud propusera. Para isso, abordarei seus principais textos, partindo de "Os três ensaios da teoria da sexualidade" (FREUD, 1905 [2006]) que demarca o início da teoria sexual, ou melhor, do sujeito preso à sua sexualidade infantil. No final, avançarei até seus escritos dos anos 1930, quando Freud, por meio de sua prática analítica, descreve a enigmática sexualidade feminina.

Freud (1905 [2006]), ao levar em conta a diferenciação entre os sexos feminino e masculino (na puberdade), constatou que, ao tornar-se mulher, faz-se necessário um novo recalcamento, o qual acaba por suprimir parte da sexualidade infantil e a prepara para a troca genital dominante, isto é, do clitóris para a vagina. No caso do homem, ele é levado a aumentar sua atividade sexual, como também manterá conservada a zona dominante de sua atividade sexual desde a infância. Em função disto, no texto "Sobre a tendência universal à depreciação na esfera do amor - Contribuições à Psicologia do Amor II", Freud (1912 [1996]) concluiu que a sexualidade infantil culmina no complexo de Édipo, o qual, por sua vez, influencia de maneira decisiva a sexualidade do adulto, pois a forma como a barreira contra o incesto vai recalcar, transformar ou dissolver este complexo, sobredeterminará um maior ou menor êxito do sujeito na sua vida amorosa.

No ano de 1913 (Totem e tabu), foi desenvolvida uma explicação global da gênese das sociedades humanas e da religião dando um fundamento histórico ao mito de Édipo à proibição do incesto, mostrando que a história individual de cada sujeito não é mais do que a repetição da história da própria humanidade.

Dessa forma, a teoria freudiana demonstra que a proibição do incesto não surgiu de um sentimento natural de repulsa dos homens em assassinar o próprio pai como ocorrera no mito. No entanto, havia o sentimento oposto: o desejo incestuoso, pois a lei proíbe os homens de fazer aquilo a que suas pulsões os inclinam. Lei que em última instância, é o equivalente à lei da castração.

Quanto à questão da escolha do objeto, posteriormente, (FREUD, 1923 [1996]) no texto "A Organização Genital Infantil: Uma interpolação na teoria da sexualidade" faz uma retificação, introduzindo a fase fálica como uma fase da vida sexual infantil, na 
qual já haveria certo grau de convergência das pulsões sexuais para um objeto determinado. Entretanto, nessa fase só se reconhece o pênis.

Portanto, Freud (1923[1996]) dividiu o desenvolvimento da organização sexual em duas fases distintas, a saber: a fase pré-genital referida às organizações da vida sexual em que as zonas sexuais ainda não assumiram um papel preponderante; e a fase genital, que se institui na puberdade, quando as pulsões parciais se unem (mas permanecem parciais) e se subordinam ao primado genital, marcando assim, a passagem para a vida adulta.

Com relação às fases que marcam o desenvolvimento da organização sexual, Freud, após várias reformulações, definiu-as subdividindo-as em quatro: a fase oral, a sádico-anal, a fálica e a genital. Elas foram assim definidas em função da evolução do sujeito e sua relação com as zonas erógenas.

No texto “A dissolução do complexo de Édipo", Freud (1924 [2006]) enfatizou pela primeira vez o diferente curso da sexualidade nas meninas e nos meninos, principalmente no que se refere à questão edípica. A saída do Édipo, no menino, se dá pelo temor à castração. Já na menina, a castração é um fato predeterminado.

Freud (op.cit.) explica, ao nos situar a fase fálica, que, diferentemente do homem, a mulher não vivencia a castração da mesma forma. E em 1972-1973, Lacan faz do gozo fálico uma função, ao estabelecer as fórmulas da sexuação sob referenciais aristotélicos, que na verdade, se originam da teoria freudiana sobre o primado do falo.

Anteriormente, em "A organização genital infantil", Freud (1923 [1996]) já havia inserido o complexo de castração ${ }^{1}$, como conceito central no conjunto de sua teoria do desenvolvimento sexual, em que relacionou este complexo com o de Édipo, reconhecendo ambos como universais. Nesse mesmo texto, introduziu uma fase complementar à sexualidade infantil: a fase fálica. Esta última é contemporânea ao complexo de Édipo e é caracterizada pela ausência de representação psíquica do sexo feminino, organizando-se então, a diferença sexual em torno da posse ou não do falo. "A antítese aqui é entre possuir um órgão genital masculino ou ser castrado" (FREUD, op. cit., p. 161).

\footnotetext{
${ }^{1}$ Segundo Freud (1923 [1996]), O complexo de castração, além de ser uma consequência que constata a diferença entre os sexos, é uma forma de organizar a diferença psiquicamente, também é produto da rememoração ou atualização da ameaça de castração que é ouvida particularmente em ocasiões quando o menino pratica a masturbação. Prática esta, considerada pelo autor como uma forma de descarga genital da excitação sexual presente no complexo de Édipo, assim como em anos posteriores cuja importância deve-se a esse relacionamento.
} 
Também nesse momento, para Freud (Ibidem), o complexo de Édipo da menina culmina num desejo de receber do pai um bebê como presente ou como um substituto do pênis. Porém, esse desejo não se realiza e o complexo de Édipo acaba por ser abandonado, restando apenas os desejos de possuir um pênis e um bebê do pai investidos no inconsciente da mulher. Entretanto, apesar de relatar a diferença entre os sexos pela ótica do desenvolvimento sexual de cada um, fora apenas em "Algumas distinções psíquicas da Distinção Anatômica entre os sexos" que Freud (1925 [2006]) iniciou o desenvolvimento de forma mais consistente sobre a questão sexual e psíquica das mulheres. Acrescentou ao Édipo, a tese da libido única de essência masculina, provocando uma dissimetria entre as organizações edipianas feminina e masculina. De acordo com essa tese, não há um paralelismo exato entre o Édipo masculino e feminino, uma vez que se o menino sai do Édipo por meio da angústia de castração, a menina ingressa nele pela descoberta da castração, afirmando o quão comum é o fato de algumas mulheres serem ligadas intensamente ao pai, assim como desejam ter um filho deste. Isso pode ser gerado por algo que na menina é diferente do menino: o complexo de Édipo aqui possui uma vasta pré-história.

Portanto, tanto no menino como na menina, o primeiro passo na fase fálica é o investimento fálico que ambos fazem na figura da mãe por essa libido de essência masculina. Num segundo momento, a descoberta da zona genital é dada sem ser da ordem psíquica, inicialmente. $\mathrm{O}$ que significa que nos primórdios da fase fálica das meninas, elas percebem o pênis de um homem próximo a elas, concluindo que esse órgão é superior. É deste modo que se origina a inveja do pênis (Penisneid). A menina, contudo, pode-se dizer mais prática, pois vê sua falta e quer completá-la. O que fora chamado de complexo de masculinidade pode tomar vários direcionamentos, podendo prejudicar o seu desenvolvimento no sentido da feminilidade. O acreditar que terá um pênis pode permanecer até uma idade avançada, gerando ações estranhas e sem sentido. Também pode ocorrer, um processo que Freud (op. cit.) nomeou de desmentido (“Verleugnung”), que é um processo em que - enquanto criança passa desapercebido, sem problema algum - quando em idade avançada corresponderia a uma psicose. Podese concluir, assim, que nas meninas, diferentemente dos meninos, o complexo de Édipo é uma formação secundária, sendo o complexo de castração algo que o precede e prepara para a dissolução do complexo de Édipo. 
Já no início da década de 30, Freud (1927-1931[1996]) ampliou sua obra ao elaborar seu texto "Sexualidade feminina", enfatizando que, igualmente como ocorre no menino, também pela menina a mãe passa a ser investida falicamente, sendo-lhe atribuída impulsos de desejo. Desta forma, Freud (op. cit.) afirma que a menina atravessa uma fase negativa do complexo de Édipo antes de ingressar na positiva, sendo o seu pai visto por ela, num primeiro momento, como um rival causador de problemas. Além disso, reforçou que na mulher as principais ocorrências sexuais da infância ocorrem em relação ao clitóris, o qual desempenha nela um papel homólogo ao pênis no menino durante a sua ligação pré-edipiana à mãe. Após a fase com a predominância de uma atividade clitoridiana (de caráter masculino), a outra fase é denominada por um investimento sexual da vagina que passa a ser o órgão genital central na atividade sexual da mulher (feminilidade).

Em suma, Freud colocou dentre os fatores determinantes pelas circunstâncias da própria sexualidade infantil, o complexo de castração, pois é o mais forte e importante para afastar a menina da mãe. Esse reconhecimento, por parte da menina, leva-a abandonar seu primeiro objeto sexual (a mãe) e a dirigir-se ao pai, ao sexo oposto. Isto faz com que a menina desenvolva sua feminilidade.

Em seu artigo "Feminilidade", Freud (1932-1933 [2006]) ressaltou novamente o papel preponderante que a descoberta da castração exerce sobre a estruturação do aparelho psíquico e da subjetividade das mulheres. Afirmou que essa descoberta representa um marco decisivo no crescimento da menina, uma vez que a partir desse momento abrem-se três linhas de desenvolvimento possíveis: uma que conduz à inibição sexual ou à neurose, outra que leva à modificação do caráter no sentido de um complexo de masculinidade e, a terceira, que a direciona no caminho da feminilidade normal. É importante frisar que Freud nunca atribuiu ao pai a responsabilidade dos desapontamentos que a menina foi adquirindo, às vezes se direcionado a um complexo de masculinidade, uma vez que a menina que está destinada a se tornar feminina não é poupada destes desapontamentos.

Quanto ao terceiro caminho, caso a menina não perca demasiados elementos por meio do recalque e do se fixar na masculinidade, a sua feminilidade pode vir a ser seu rumo natural, isto é, a menina muda ao mesmo tempo de sexo e de objeto, voltando-se para o pai, do qual espera um bebê, o que seria o substituto do pênis, na realidade. 
É imprescindível enfatizar, na teoria freudiana, que mesmo o desenvolvimento da menina tendo percorrido de maneira adequada rumo à feminilidade, ele continua exposto a perturbações motivadas pelos fenômenos residuais do período pré-edipiano. Isso, nos leva a concluir, tal como Soler (2003) que, se o Édipo produz o homem, ele não produz a mulher e será em Lacan que veremos de maneira mais elucidada esse tema.

Com suporte da lógica - na verdade, de uma longa tradição lógica, uma vez que sua primeira referência é Aristóteles -, Lacan (1971 [2009]) retomou inicialmente o mito edipiano articulando o conceito de falo e de castração, propondo quatro fórmulas quânticas da sexuação, que divididas em partes, permitem-lhe elaborar a questão da diferença dos sexos em termos de sexuação, que nada tem a ver com a anatomia, mas com o modo com o qual cada ser falante se posiciona em relação ao falo e à castração. $\mathrm{O}$ falo é considerado uma paixão pelo sentido do sexo e também como "a objeção de consciência, feita por um dos dois seres sexuados, ao serviço a ser prestado ao outro. (LACAN, 1972 c:15)" Nem o homem, nem a mulher sabe de um ou do outro. A função fálica é enigmática e o enigma que o falo possui na psicanálise surge em função do inconsciente, ou seja, por aparecer sempre uma não complementaridade nas relações, pelo contrário, há sempre impasses e isto verificamos cotidianamente na clínica.

Lacan (op. cit.) começou a tratar da sexuação logicamente no Livro 18, recolhendo na obra de Freud vários pontos concernentes ao tema acrescidos de uma estrutura de ordem lógica. Ao tomar os quantificadores, elaborou quatro fórmulas que são as seguintes:

\begin{tabular}{|c|c|c|c|}
\hline ヨ. $\chi$ & $\overline{\Phi . \chi}$ & $\overline{\exists . \chi}$ & $\overline{\Phi . \chi}$ \\
\hline$\forall . \chi$ & $\Phi . \chi$ & $\overline{\forall . \chi}$ & $\Phi . \chi$ \\
\hline
\end{tabular}

Do lado esquerdo, tem-se o lado dos homens com duas fórmulas e do lado direito, duas outras fórmulas para as mulheres. Do lado esquerdo, há uma fórmula universal que designa que todo x está submetido à função fálica, portanto, à castração. Essa é a regra e como tal, suporta-se numa exceção, garantida pela fórmula de cima, que indica que há ao-menos-um, que é como Lacan o chama, que não está submetido à função fálica, isto é, à castração. É esse ao-menos-um que dá consistência ao conjunto 
de todos os homens são castrados. Do lado direito e abaixo, não há um universal, pois não-toda mulher está submetida à função fálica. Isso porque não há, como no lado homem, o ao-menos-um que garanta o conjunto de todas as mulheres. Desse lado, não existe x que não esteja submetido à função fálica, sendo por essa razão que, elas, as mulheres, não estão, de todo, submetidas à referida função fálica.

É por essa vertente que Lacan (1972-1973 [1985]) vai tratar especificamente da questão da feminilidade e da sexualidade propriamente feminina, propondo, em $O$ Seminário, Livro 20: Mais, ainda, um quadro acrescido às fórmulas quânticas da sexuação para tratar justamente da questão dos gozos para o homem e para a mulher.

\begin{tabular}{|c|c|}
\hline$\exists \chi \bar{\Phi} \chi$ & $\overline{\bar{\exists}} \chi \bar{\Phi} \chi$ \\
\hline$\forall \chi \Phi \chi$ & $\bar{\nabla} \chi \Phi \chi$ \\
\hline$\$$ & $a$ \\
\hline$\Phi \leftarrow$ & $\mathrm{S}(\mathbb{A})$ \\
\hline
\end{tabular}

É do lado homem que Lacan (op. cit., p. 105) incluiu o sujeito do inconsciente, o sujeito barrado que se constitui circularmente no campo do Outro da linguagem, ao preço de perdas parciais de gozo que vão centrar-se em torno do objeto pequeno $a$, que, tal como podemos observar no quadro, está no quadrante do feminino. É aí nessa divisão que é possível ver perfeitamente toda a divisão que sempre foi evidenciada por Lacan ao longo de seu ensino em torno da questão da fantasia. Enquanto o sujeito está do lado masculino, o objeto da sua fantasia está no lado feminino e é nessa relação entre o sujeito e o objeto a que o gozo que Lacan chamou de fálico se introduz. O gozo fálico, é o que há de propriamente masculino. É o gozo que pode ser dito, metaforizado, que faz seu retorno extemporâneo nas formações do inconsciente, por exemplo.

No lado mulher das fórmulas quânticas, Lacan (op./cit.) articula a hiância entre um lado que ela ocupa: o de nada certificar que ela não participe da lógica fálica, ( $\exists x$ $\phi x)$, ou seja, ele afirma a não existência de pelo menos um que tenha escapado à 
castração. Do outro lado, há a não-toda mulher inscrita na função fálica ( $\forall \mathrm{x} \phi \mathrm{x})$. Isso quer dizer que é impossível falar de todas as mulheres. Elas ficam, portanto, num conjunto aberto, como indeterminadas. Existe apenas, cada mulher que se faz uma a uma. É por este motivo que Lacan afirma que é por intermédio das mulheres que se vê o quanto a existência de Um pai é necessária. É no Seminário XIX, O Saber do Psicanalista, na lição de 04 de novembro de 1971, que Lacan apresenta algumas classificações lógicas.

Em primeiro lugar, faz equivalência entre o "Necessário" e a existência de Um pai; em segundo, equivale o "impossível" com a existência d'A mulher, em terceiro lugar, aproxima o "possível" com o conjunto dos homens e, por último, atribui ao "contingente" à semelhança da virilidade das mulheres.

Freud, então, diante da incógnita de onde surge a hostilidade feminina, conclui que é devido à inveja do pênis. Ele diz: "A sexualidade inacabada da mulher é descarregada no homem" (FREUD, 1917[1996], p. 78), principalmente por vingança e, em segundo lugar, por amargura. Lacan, por sua vez, direcionou essa questão fora da ênfase freudiana que se atém ao desenvolvimento. Ele priorizou - sem negar a existência da Penisneid e da hostilidade da mulher - saber quais são as possibilidades femininas para reconhecer um homem como ele é, além de poder gozar com o pênis dele. Inicialmente, Lacan parte da castração simbólica, transformando a oposição de Freud entre a satisfação feminina e o fantasma da castração em causalidade. Para uma mulher chegar ao gozo, ela precisa de "seus fantasmas castradores" (MOREL, 1996, p.135) que não foram totalmente simbolizados. Diante disso, Lacan (1958[1998]) pode responder de que modo uma mulher atinge o gozo sexual; logo, de onde ela não é frígida.

A condição de gozo feminino é, consequentemente, do órgão viril encontrado num retorno do amor para o desejo, fazendo um circuito do gozo. Através do "incubo ideal" (do latim incubare, termo que remete ao gozo e é um demônio que atormenta as mulheres à noite), uma receptividade precisa ser deslocada "como sensibilidade de invólucro para o pênis" (LACAN, 1958[1998], p.733). Assim, o autor situa o gozo para fora do corpo feminino, no caminho que o gozo faz do incubo ao pênis como fetiche. Isso demonstra que, "atrás do véu” enfatiza-se o quão próximo é o gozo do amor feminino, explicitando a supervalorização do amor das mulheres. $\mathrm{O}$ amor absoluto chega por intermédio do ideal ligado ao termo "incubo" e ainda o transforma mais a tal trajetória em uma fórmula: "Somente o amor permite ao gozo condescender ao desejo" (LACAN, 1962-1963[2005], p.197). 
A mulher está entre o tudo e o nada. Ela se encontra entre o centro e a ausência. Pode ser dito que ela está entre o gozo fálico e o lugar do vazio d’A mulher, gozo que é indizível. Conclui-se que a mulher tem uma parte inscrita no Simbólico e outra que não e que estaria, portanto, no Real. "A título do que se situa pelo discurso, pois, se o que aqui coloco é verdadeiro, isto é, que a mulher não é toda, há sempre alguma coisa nela que escapa ao discurso." (LACAN, 1972-1973 [1985], p. 46). Se uma mulher é nãotoda inscrita no Simbólico, ela tem uma parte no Real que seria a sua parte louca e outra no Simbólico, a sua parte não louca.

\section{Considerações finais}

A respeito do fenômeno da devastação, conclui-se que nada existe de semelhante no que diz respeito às mulheres. Lacan (1972-1973 [1985]) utilizou a expressão em relação ao homem, em mulher-sintoma e, quanto ao lado feminino, utilizou o termo devastação ou "aflição": o homem-devastação. A expressão devastação fora utilizada por Lacan, inicialmente, para descrever a relação mãe e filha. Ele ainda corrobora, com a teoria de Freud de que o homem é quem herda a relação da mãe com a filha, principalmente, sobre as censuras concedidas à mãe. Porém, Lacan discorda quanto à reivindicação exclusiva ao falar da devastação. Ela se encontra aí, mas se localiza em outra ordem sem ser a ordem fálica. Isso só se verifica quando vai ao encontro do gozo feminino, já que ela é efeito dele. O orgasmo e o sintoma possuem o valor de um "esvaecimento do sujeito como dividido" (SOLER, 2003, p.184), pois o que se busca é um gozo do próprio sujeito. Ainda no tocante à devastação, observa-se que se encontram variedades em relação aos níveis diferentes desse fenômeno - que precisariam ser investigados com mais detalhes -, assim como existem diversas possibilidades de atravessá-lo. Também há aquelas que não conseguem sair da devastação, sendo assim, elas atuarão em outra mulher, de maneira extremamente insana, ou com homens, quando estes ocupam lugar daquela que foi seu primeiro objeto de investimento de desejo.

Se a devastação não for atravessada, há a possibilidade de a mulher paralisar-se frente à Outra que a arrebata, como se já não houvesse sujeito em seu próprio corpo. É o que acontece, por exemplo, com a personagem Lol V. Stein de Marguerite Duras (1964), 
razão da bela homenagem que Lacan (1965 [2003]) presta à autora. O caminho da mulher, ao identificar-se a um brilho no olhar do Outro para construir sua própria consistência tem um lado criativo, mas pode tornar-se subitamente trágico.

Devo considerar, em primeiro lugar, que a relação mãe-filha é uma relação entre corpos femininos, em que uma parte não é simbolizada. Essa parte não simbolizada atua como uma falta que proporciona a dependência de uma com a outra, e a mistura entre elas pode acarretar numa indistinção. Ao mesmo tempo, a imagem que a filha tem de sua mãe funde-se com a imagem de si, podendo resultar num terror e encanto sentido pela filha. Freud (1915 [2006]) enalteceu isto ao descrever sobre o caso da mulher paranoica. Ele articulou o fascínio com o persecutório ao relatar a visão e o que a mãe representa para a filha. A filha vê no corpo da mãe uma possível imagem de um corpo de mulher para que o homem mantenha o desejo por ela. A menina jamais encontrará o que procura: o enigma da sexualidade materna. A criança se depara com a falta da mãe, mas não pela falta de um pênis real, mas no significante que ela deveria possuir para representar o feminino. Mãe e filha trocam ideias entre si, confidenciam seus segredos, com uma confiança cega no que diz respeito às intimidades entre ambas. Porém, é evidente que a mãe possui um poder maior sobre essas posições que elas mantêm, já que ela é a responsável pelo desenvolvimento de sua filha.

A criança é um objeto que primeiramente surge no mundo como real, um objeto erótico usado pelo outro. Isso perpassa vários momentos da sua constituição até a ocasião em que possa constituir uma exceção como o que Lacan (1968-1969 [2008], p. 220) propôs: "não existe relação sexual". No entanto, Lacan (1975-1976 [2005], p. 104) localiza no final de seu ensino, a seguinte frase: "Não existe relação sexual exceto entre gerações”. Assim, a criança como corpo erotizado pela mãe constitui um limite que evoca outra formulação: "Não existe gozo do corpo do Outro. E é verdade que para a mulher, a criança, reduzida ao seu valor fálico (segundo Freud), seja também real. Com esse rebento de corpo, a mulher vê aparecer no real da mesma vida, $S(\mathbb{A})$ o equivalente de sua própria falta”. (op.cit.). Portanto, a erotização do corpo da filha feita pela mãe, e que está na base da constituição do seu narcisismo, é uma das condições para o fenômeno da devastação. Até que ponto, diante disso, poderia considerar a devastação como constituindo uma exceção à não existência da relação sexual? 


\section{Referências}

ARONOFSKY, D. et al. Cisne Negro. Estados Unidos, Fox Searchlight Pictures, 108 minutos. 2010.

FREUD, S. (1905). Três Ensaios Sobre a Teoria da Sexualidade. Obras Completas, ESB, v.VII. Rio de Janeiro: Imago, 2006.

. (1912). Sobre a Tendência Universal à Depreciação na Esfera do Amor

(Contribuições à Psicologia do Amor II). Obras Completas, ESB, v.XI. Rio de Janeiro: Imago, 1996.

. (1913). Totem e Tabu. Obras Completas, ESB. v. XIII. Rio de Janeiro:

Imago, 2006.

. (1915). Um caso de paranoia que contraria a teoria psicanalitica da doença.

Obras Completas, ESB, v. XIV. Rio de Janeiro: Imago, 2006.

(1920) A psicogênese de um caso de homossexualismo numa mulher. Obras

Completas, ESB. v. XVIII. Rio de Janeiro: Imago, 2006.

. (1923). A organização Genital Infantil. Obras Completas, ESB. v. XIX. Rio de Janeiro: Imago, 1996.

. (1924). A dissolução do Complexo de Édipo. Obras Completas, ESB. v.XIX. Rio de Janeiro: Imago, 1996.

. (1925). Algumas consequências psíquicas da distinção anatômica entre os sexos.

Obras Completas, ESB, v. XIX. Rio de Janeiro: Imago, 2006.

(1927-1931). Sexualidade Feminina. Obras Completas, ESB, v. XXI. Rio de Janeiro: Imago, 1996.

. (1932-1933). Feminilidade. Obras Completas, ESB, v. XXII. Rio de Janeiro: Imago, 2006.

FORBES, J. (Org.), HARARI, A., BENETI, A., PELUSO, A., PAULOSKY, D., MOREL, G. et. al. Psicanálise: problemas ao feminino. Campinas: Papirus, 1996. 
LACAN, J. (1958) "Juventude de Gide ou a letra e o desejo". In.: Escritos .

Rio de Janeiro: Jorge Zahar Editor, 1998, p. 749-775

. (1962-1963). O Seminário, Livro 10 - A Angústia. Rio de Janeiro: Jorge

Zahar Editor, 2005.

. (1965). Homenagem a Marguerite Duras pelo arrebatamento de Lol. V.

Stein. Outros Escritos. . Rio de Janeiro: Jorge Zahar Editor, 2003, p.198-205.

. (1968-1969) O Seminário, Livro 16 - De um Outro ao outro. Zahar, Rio de

Janeiro, 2008.

(1971) O Seminário, Livro 18 - De um discurso que não seria do semblante. Rio de Janeiro: Jorge Zahar Editor, 2009.

. (1971-1972) O Seminário, Livro 19 - ... ou pior. Rio de Janeiro: Jorge Zahar Editor, 2012.

(1972). O Aturdito. In.: . Outros escritos. Rio de Janeiro: Jorge

Zahar Editor, 2003. p. 448-497.

. (1972-1973). O Seminário, Livro 20 - Mais, ainda. Rio de Janeiro: Jorge

Zahar Editor, 1985.

(1975-1976). Seminário 23. O sinthoma, inédito

SOLER, C. O que Lacan dizia das mulheres. Rio de Janeiro: Jorge Zahar Editor, 2003. 